\title{
Factors affecting the number of teats in pigs
}

\author{
L. C. Drickamer ${ }^{1 *}$, T. L. Rosenthal ${ }^{2}$ and R. D. Arthur ${ }^{2}$ \\ ${ }^{1}$ Department of Zoology, Southern Illinois University, Carbondale, IL 62901, USA; and \\ ${ }^{2}$ Department of Animal Science, Food and Nutrition, Southern Illinois University, Carbondale, IL 62901, USA
}

\begin{abstract}
The factors that affect the number of teats in pigs are of interest for both biological and practical reasons. Previous work indicates that there is a genetic component, principally from the dam. The proportion of males in a litter appears to be related to the anogenital distance of the gilts in the litter, possibly as a result of the intrauterine position effect. The present study investigated whether litter size, litter sex ratio, anogenital distance, crown-rump length, distance from base of skull to base of tail, and the number of teats on the dam and boar affected the number of teats on gilts. Stepwise multiple regression on litter mean values (adjusted $r^{2}=0.178$ ) indicated that two factors were significant: the number of teats on the dam (standard coefficient 0.311 ) and the proportion of males in the litter (standard coefficient -0.282 ). A greater number of teats on the dam and a lower proportion of males in the litter resulted in a greater number of teats on the gilt. When the analysis was run using individual gilts as the independent units (adjusted $r^{2}=0.073$ ), the number of teats on the dam (standard coefficient 0.207 ), the proportion of males in the litter (standard coefficient -0.135), and the weaning weight of the gilt (standard coefficient 0.083 ) were all significant predictors of the number of teats. This evidence suggests that teat number in female pigs is related to the proportion of males in the litter.
\end{abstract}

\section{Introduction}

One factor known to affect teat number in pigs is genetic inheritance from the dam (Allen et al., 1959; Enfield and Rempel, 1961). Inheritance from the boar may also affect teat number. The intrauterine position (IUP) of a fetus affects physiological, morphological, and behavioural traits in rodents (vom Saal, 1981, 1989), including the anogenital distance (AGD). The anogenital distance is related to IUP for mice (Vandenbergh and Huggett, 1995); females positioned in utero between two males have larger AGDs than females positioned between two females. In domestic pigs, the proportion of males in a litter has a significant effect on the AGD of gilts in that litter (Drickamer et al., 1997). The higher the proportion of males in the litter, the larger the average AGD of gilts in that litter. Furthermore, females from litters with $>67 \%$ males were more likely to exhibit conception failure.

Kratochwil (1971) and Kratochwil and Schwartz (1976) reported that the development of mammary tissue in mice is influenced by androgens. The presence of androgens inhibits mammary tissue development. It is possible that androgens from one fetus influence the process of mammary tissue development in neighbouring fetuses. In pigs, the number of teats ranges from 10 to 20 . Therefore, pigs may be a good model species for a first test of the possibility that teat

'Present address: Department of Biological Sciences, Northern Arizona University, Flagstaff, AZ 86011-5640, USA.

Received 24 April 1998. number varies with in utero exposure to androgen. In addition, because teat number is one of several factors used to evaluate gilts to decide whether to retain them for breeding stock, it is of some interest to ascertain what factors influence teat number. The present study tested the hypothesis that the proportion of males in the litter of a gilt affects the expression of the number of teats. Several other factors that may influence the number of teats were also tested.

\section{Materials and Methods}

All data were collected at the Southern Illinois University Swine Center at Carbondale, IL. The Center involves a standard swine operation with a primary stock consisting of a Duroc-Hampshire-Yorkshire cross scheme. All pigs were maintained with water ad libitum and were fed a corn-soybean meal base diet. During gestation, groups of sows were housed in a curtain-sided, monosloped, naturally ventilated facility with partial slotted floors. Sows were moved to the farrowing facility 2-4 days before expected parturition. All sows were farrowed in a single, mechanically ventilated room containing 30 crates with slotted flooring. The crates were over a $1.3 \mathrm{~m}$ deep ventilated manure pit, which was pumped between farrowing groups. The period of lactation in this management system averages 24 days with a range of 21-28 days. All diets met or exceeded NRC recommendations (National Research Council, 1988) for gestating and lactating sows. 
Three separate tests were conducted to assess the possible factors influencing the number of teats on gilts. The first two tests involved measurements made on newborn gilts in the facility and the third test used a long-term database containing information on litters produced at the Swine Center. The first two tests were conducted separately because complete information on one independent variable was not available for all litters.

\section{Experiment 1}

All 637 gilts born alive in 151 litters farrowed between October 1996 and June 1997 were used. Within 3 days after birth (birth = day 1), four measurements were made on each gilt: body mass (to the nearest $0.1 \mathrm{~kg}$ ), crown-rump length (to the nearest $0.1 \mathrm{~mm}$ ), anogenital distance (AGD) (to the nearest $0.1 \mathrm{~mm}$ ), and the number of teats. The anogenital distance measurement was made with dial calipers and consisted of the shortest distance between the nearest point of the anus and the genital opening on each gilt. Each gilt was also weighed to the nearest $0.1 \mathrm{~kg}$ at 21 days of age. Information was obtained on the sexes of all pigs born alive or dead in each litter to calculate the sex ratio as a proportion of males in the litter. Finally, information was obtained on the number of teats on the sow for each litter. Each sow was represented only once in the dataset. The number of teats on boars was analysed separately because each boar sired multiple litters within the dataset and using them in the same analysis could have violated the assumption of independence. In addition, all boars had either 12 or 14 teats and so there was likely to be insufficient variation in the number of teats on boars to provide an adequate test of this effect in a multiple regression model. Sow breed was not tested in these analyses because all sows were hybrids.

For one analysis, mean values were computed within each litter for body mass, crown-rump length, anogenital distance, and number of teats. A stepwise multiple regression procedure (STATVIEW 4.5, Abacus Corp., 1996) was used to test the principal question concerning predictors of the number of teats. The dependent variable was the mean number of teats per litter. The independent variables were body mass at birth, body mass at weaning, crown-rump length, anogenital distance, the proportion of males in the litter, litter size, the number of teats on the sow, and the number of teats on the boar. For a second analysis, individual gilts were used as the test unit. The same independent and dependent measures were used.

Two regression analyses were conducted to investigate the possible genetic effects of the number of teats on boars. For one regression analysis, the number of teats on each boar was tested against the litter means for the number of teats on the gilts in the litters they sired. For the other regression analysis, the number of teats on each boar was tested against the number of teats on the individual gilts that they sired.

\section{Experiment 2}

For this analysis, all gilts from 48 litters born during August, September, and October 1997 were used. All of the data gathered in Expt 1 were used in this test. In addition, the distance from the base of the skull to the base of the tail (to the nearest $0.1 \mathrm{~mm}$ ) was measured. This additional measurement was used as a further test of any possible allometric effect on the number of teats. As in Expt 1, a stepwise multiple regression was used to test for predictors of the number of teats. An analysis was run using litter mean values with the same dependent variables as in Expt 1. All of the independent variables were the same, with the addition of the measurement of distance from the base of the skull to the base of the tail.

\section{Experiment 3}

For this analysis, 73 sows from Expts 1 and 2 whose teat number had been counted when they bore litters were used. In addition, the record of each sow in a long-term database including information concerning her birth litter size and sex ratio were included in this analysis. A stepwise multiple regression analysis was then conducted, with the number of teats on the sow as the dependent variable. The independent variables were the birth litter size of the sow, the proportion of males in that birth litter, the body mass of the sow at birth, and the body mass of the sow at 21 days of age. Data on the number of teats on the mothers of these sows were not available.

\section{Results}

\section{Experiment 1}

The stepwise multiple regression procedure using litters needed two steps, at which point $r=0.434$ and adjusted $r^{2}=0.178$. Two independent variables were significant predictors of the number of teats on newborn gilts: the number of teats on the dam and the proportion of males in the litter (Table 1). The stepwise multiple regression procedure using individual gilts produced three significant factors ( $r=0.277$; adjusted $r^{2}=0.073$ ): the number of teats on the dam, the proportion of males in the litter, and the weaning weight were all significant factors affecting teat number (Table 1).

The regression analysis of the number of teats on the boars against the litter means of the number of teats on the gilts they sired was not significant $(r=0.094 ; \mathrm{df}=155 ; P=0.2517)$. The similar analysis using the number of teats on the individual gilts as the dependent variable approached significance $(r=0.076 ; \mathrm{df}=635 ; P=0.0551)$.

\section{Experiment 2}

The stepwise multiple regression procedure needed two steps, at which point $r=0.461$ and adjusted $r^{2}=0.213$. Two independent variables were significant predictors of the number of teats on newborn gilts: the proportion of males in the litter and the number of teats on the dam (Table 1).

\section{Experiment 3}

The stepwise multiple regression procedure needed two steps, at which point $r=0.368$ and the adjusted $r^{2}=0.110$. 
Table 1. Factors predicting the number of teats expressed in female swine from three separate analyses

\begin{tabular}{|c|c|c|c|}
\hline Factor & Coefficient & Standard coefficient & $F$ value \\
\hline \multicolumn{4}{|c|}{$\begin{array}{l}\text { Analysis using litter means and seven independent variables } \\
\text { (Expt } 1 ; n=151 \text { litters) }\end{array}$} \\
\hline Proportion of males in birth litter & $-0.011 \pm 0.003$ & -0.282 & 14.427 \\
\hline Number of teats of dam & $0.214 \pm 0.051$ & 0.311 & 17.552 \\
\hline \multicolumn{4}{|c|}{$\begin{array}{l}\text { Analysis using individual gilts and seven independent variables } \\
\text { (Expt } 1 ; n=637 \text { gilts) }\end{array}$} \\
\hline Proportion of males in birth litter & $-0.009 \pm 0.003$ & -0.135 & 12.183 \\
\hline Number of teats of dam & $0.219 \pm 0.041$ & 0.207 & 29.151 \\
\hline Weaning weight (kg) & $0.098 \pm 0.045$ & 0.083 & 4.712 \\
\hline \multicolumn{4}{|c|}{$\begin{array}{l}\text { Analysis using litters and eight independent variables } \\
\text { (Expt } 2 ; n=48 \text { litters) }\end{array}$} \\
\hline Proportion of males in birth litter & $-0.014 \pm 0.006$ & -0.311 & 5.420 \\
\hline Number of teats of dam & $0.224 \pm 0.100$ & 0.298 & 4.987 \\
\hline \multicolumn{4}{|c|}{$\begin{array}{l}\text { Analysis using sows and four independent variables } \\
\text { (Expt } 3 ; n=78 \text { sows) }\end{array}$} \\
\hline Proportion of males in birth litter & $-0.017 \pm 0.007$ & -0.267 & 5.743 \\
\hline Birth weight (kg) & $0.357 \pm 0.149$ & 0.266 & 5.730 \\
\hline
\end{tabular}

Two independent variables were significant predictors of the number of teats on these sows: the proportion of males in the birth litter and birth weight (Table 1).

\section{Discussion}

The results of the present study confirm that the number of teats expressed on gilts is a function of inheritance from the dam (Allen et al., 1959; Enfield and Rempel, 1961; Brevern et al., 1994; Ligonesche et al., 1995) and indicate that the proportion of males in the litter is also a significant factor influencing the number of teats expressed on gilts. The fact that the proportion of males in a litter can affect the number of teats suggests that there is some form of environmental influence in utero. One possible explanation involves prenatal hormones and the IUP of the fetus (vom Saal and Bronson, 1978; vom Saal, 1989). Female mouse fetuses that are positioned between two males in utero are masculinized to various degrees with respect to their morphology, physiology, and behaviour. In mice, there is a clear relationship between the proportion of males in a litter, the IUP and the anogenital distance for the female progeny (Vandenbergh and Huggett, 1995). This relationship between the proportion of males in a litter and the anogenital distance for females is also present in pigs (Drickamer et al., 1997). Furthermore, gilts and sows from litters with high proportions of males have significant problems with conception.

In the present study, for both analyses involving multiple factors and the number of teats on gilts, the proportion of the total variance in the number of teats that was accounted for by the two significant factors (the number of teats on dams and the proportion of males in the litter) was relatively low. Additional factors, not tested here, must contribute to the variation in the number of teats. The number of teats on dams and boars, the two primary possible genetic components, were included in our analyses and so it is likely that these additional factors are environmental.

Analyses using individual gilts and sows revealed that body mass at 21 days (weaning) or at birth may predict the number of teats expressed on sows. This finding suggests that there is some (allometric) effect of body proportions on the number of teats expressed, as has been reported by Ligonesche et al. (1995). However, two analyses using litter means with newborn gilts failed to reveal that body weight at birth or at 21 days of age affected the number of teats. In addition, neither of the linear measurements made, crown-rump length or distance from the base of the skull to the base of the tail, were significant factors affecting the number of teats. Therefore, any allometric effects on the number of teats expressed are likely to be weak. In the present study, there was generally no relationship between body measurements and the number of teats.

This is the first report, to our knowledge, of the possible effect of the proportion of males in a litter, which may be mediated by IUP, on the number of teats on a mammal. A possible embryonic basis for the influence of testosterone on developing mammary tissue has been established in mice (Kratochwil, 1971; Kratochwil and Schwartz, 1976). The mechanism in mice involves the suppression of rudimentary mammary tissue by androgens. Thus, mammary tissue in male mice ceases differentiation during intrauterine development. In the absence of androgens, as in normally developing females, the mammary tissue continues to differentiate. A female fetus positioned between two males could be affected by androgens from those males, for example, the androgen could partially suppress mammary development. A similar mechanism may operate in pigs, although additional research is needed to test this hypothesis.

The authors thank the student workers who have assisted with the care and management of the swine herd at the Southern Illinois 
University Swine Center. They thank W. Muhlach for locating references concerning mammary tissue development and two anonymous reviewers for helpful comments on an earlier version of this manuscript. This research was supported by grants from the Illinois Pork Producers Association and the Council for Food and Agricultural Research in Illinois to R. D. Arthur, L. C. Drickamer and T. L. Rosenthal.

\section{References}

Allen AD, Trimble LF and Lasley JF (1959) Inheritance of nipple numbers in swine and the relationship to performance Research Bulletin of the University of Missouri College of Agriculture Experiment Station 694 1-15

Brevern VNV, Schimpf B, Wörner R and Swalve H (1994) Paramterschätzung für Zitzenmerkmale bei Hybridsauen Züchtungskunde 66 339-348

Drickamer LC, Arthur RD and Rosenthal TL (1997) Conception failure in swine: importance of the sex ratio of a female's birth litter and tests of other factors Journal of Animal Science 75 2192-2196

Enfield FD and Rempel WE (1961) Inheritance of teat number and relationship of teat number to various maternal traits in swine lournal of Animal Science 20 876-879
Ligonesche B, Bazin C and Bidanel JP (1995) Variabilité Génétique du nombre de tétines chez le porc Journale Recherche Porcine France 27 121-126

Kratochwil K (1971) In vitro analysis of the hormonal basis for the sexual dimorphism in the embryonic development of the mouse mammary gland Journal of Embryology and Experimental Morphology 25 141-153

Kratochwil K and Schwartz P (1976) Tissue interaction in androgen response of the embryonic mammary rudiment of mouse: identification of target tissue for testosterone Proceedings of the National Academy of Sciences USA 73 $4041-4044$

National Research Council (1988) Nutrient Requirements of Swine 9th Edn. National Academy Press, Washington, DC

Statview (1996) Statview 4.5 User's Guide Abacus Concepts, Berkeley, CA

Vandenbergh JG and Huggett CL (1995) The anogenital distance index, a predictor of the intrauterine position effects on reproduction in female house mice Laboratory Animal Science 45 567-573

vom Saal FS (1981) Variation in phenotype due to random intrauterine positioning of male and female fetuses in rodents journal of Reproduction and Fertility 62 633-650

vom Saal FS (1989) Sexual differentiation in litter-bearing mammals: influence of sex of adjacent fetuses in utero. Journal of Animal Science 67 1824-1840

vom Saal FS and Bronson FH (1978) In utero proximity of female mouse fetuses to males: effects on reproductive performance during later life Biology of Reproduction 19 842-853 